\title{
The Relationship between Glycosyltransferase Production and Membrane Fatty Acid Composition of Streptococcus sanguis NCTC 7865 Grown in the Presence of Protonmotive Force Inhibitors
}

\author{
By AILEEN A. WEST, ${ }^{1 *}$ ROBERT A. WHILEY, ${ }^{2}$ PHILIP D. MARSH ${ }^{1}$ AND \\ C. WILLIAM KEEVIL \\ ${ }^{1}$ Bacterial Metabolism Research Laboratory, PHLS Centre for Applied Microbiology and \\ Research, Porton Down, Salisbury, Wiltshire SP4 0JG, UK \\ ${ }^{2}$ Department of Oral Microbiology, The London Hospital Medical College, London E1 2AD, UK
}

(Received 26 March 1987; revised 21 May 1987)

\begin{abstract}
The fatty acid composition of Streptococcus sanguis NCTC 7865 was not altered by changing the cation composition $\left(\mathrm{Na}^{+} / \mathrm{K}^{+}\right)$of the growth medium; glucosyltransferase (GTF; EC 2.4.1.5) also remained constant. In contrast, fructosyltransferase (FTF-S; EC 2.4.1.10) production was reduced by at least $50 \%$ in medium with a high $\mathrm{Na}^{+}$concentration. Growth in the presence of ionophores (gramicidin, nigericin or valinomycin) resulted in an increased proportion of saturated fatty acids, principally octadecanoic acid $\left(\mathrm{C}_{18: 0}\right)$, while the proportion of unsaturated fatty acids, predominantly octadecenoic $\left(C_{18: 1}\right)$ and hexadecenoic $\left(C_{16: 1}\right)$ acids, decreased. GTF-S production was reduced in the presence of ionophores whereas FTF-S production was completely abolished. Tween 80 significantly increased both GTF-S production and the proportion of unsaturated fatty acids in the cytoplasmic membrane; FTF-S production was unaltered by Tween 80 . The production of GTF-S was inversely proportional to the $C_{18: 0}: C_{18: 1}$ fatty acid ratio of the cytoplasmic membrane. It was concluded that FTF-S production is directly influenced by protonmotive force (pmf), whereas GTF-S production is affected more by the physical properties of the cytoplasmic membrane, in particular its fatty acid composition. However, as perturbations in pmf generation can lead to variations in membrane fatty acid composition it can be argued that pmf indirectly influences GTF production by changing the saturated : unsaturated or $\mathrm{C}_{18: 0}: \mathrm{C}_{18: 1}$ fatty acid ratio of the cytoplasmic membrane.
\end{abstract}

\section{INTRODUCTION}

Dental plaque is the film of micro-organisms, found naturally on the tooth surface, embedded in polymers of salivary and bacterial origin (the plaque matrix). The initial stages of plaque formation are mediated by specific interactions between microbial 'adhesins' and host molecules adsorbed to the enamel. Subsequent plaque accumulation is dependent on the adhesion of cells to pre-attached micro-organisms. One of the major factors in the formation of plaque, particularly in determining its properties and structural integrity, is the synthesis of extracellular polysaccharides from sucrose by glycosyltransferases (Gibbons \& van Houte, 1975). In particular, the extracellular glucosyltransferases (GTF; EC 2.4 1.5), dextransucrase (GTF-S) and mutansucrase (GTF-I), catalyse the synthesis of soluble dextran and insoluble mutan, respectively, whilst fructosyltransferases (FTF; EC 2.4.1.10) FTF-S and FTF-I catalyse soluble and insoluble fructan synthesis, respectively (Keevil et al., 1984).

\footnotetext{
Abbreviations: DMSO, dimethyl sulphoxide; GTF, glucosyltransferase; GTF-S, dextransucrase; GTF-I, mutansucrase; FTF, fructosyltransferase; FTF-S, frucrosyltransferase catalysing water-soluble fructan formation; FTF-I, fructosyltransferase catalysing water-insoluble fructan formation; pmf, protonmotive force; $\Delta \psi$, transmembrane electrical potential difference; $\Delta \mathrm{pH}$, transmembrane $\mathrm{pH}$ gradient; $\mathrm{LH}$, London Hospital medium; LHS, London Hospital high sodium ion medium; LHP, London Hospital high potassium ion medium.
} 
The production of these enzymes has been studied in our laboratory using Streptococcus sanguis NCTC 7865 because it is an early colonizer of the tooth surface and therefore probably has an important role in the formation of the dental plaque matrix (Carlsson et al., 1970; Cooney et al., 1976).

A consequence of plaque formation is the development of gradients in factors which can influence the physiology of the accumulated bacteria. As an example, the concentration of certain cations, especially $\mathrm{K}^{+}$, is higher in plaque fluid (the fluid phase of plaque) than in saliva. In laboratory studies, varying the ratio of the major cations $\left(\mathrm{Na}^{+}, \mathrm{K}^{+}\right)$gf plaque fluid was found to profoundly affect the metabolism of oral streptococci (Marsh et al., 1984; Keevil et al., 1986). In particular, a high $\mathrm{K}^{+} / \mathrm{Na}^{+}$ratio was essential for the production of FTF by $S$. sanguis NCTC 7865 with high $\mathrm{Na}^{+}$concentrations almost completely abolishing its synthesis and secretion (Keevil et al., 1983, 1984). Significantly, these cations have also been shown to modulate the generation of protonmotive force $(\mathrm{pmf})$ in oral streptococci. Both reduce the transmembrane electrical potential difference $(\Delta \psi)$, but $\mathrm{K}^{+}$is essential for the maintenance of a transmembrane $\mathrm{pH}$ gradient $(\Delta \mathrm{pH})$, whilst $\mathrm{Na}^{+}$is inhibitory (Keevil \& Hamilton, 1984a,b). Thus, the possibility of the involvement of pmf in the secretion of GTF and FTF was investigated using the ionophores valinomycin, nigericin and gramicidin. FTF production was completely inhibited by the ionophores, whereas GTF production was only slightly reduced (West et al., 1984).

Wittenberger et al. (1978) and more recently Markevics \& Jacques (1985) have studied enzyme secretion in another oral bacterium, $S$. salivarius. Tween 80 and variations in the $\mathrm{Na}^{+} / \mathrm{K}^{+}$environment were shown to alter the fatty acid composition of the cytoplasmic membrane. Markevics \& Jacques (1985) speculated that membrane fluidity rather than pmf might be responsible for GTF production. We have therefore studied the membrane fatty acid profiles of $S$. sanguis grown in high $\mathrm{Na}^{+}$or $\mathrm{K}^{+}$environments, and in the presence of ionophores or Tween 80 , to investigate the relationship between pmf generation, membrane fatty acid composition and GTF and FTF production.

\section{METHODS}

Organism. Streptococcus sanguis NCTC 7865 was maintained on blood agar plates and the viability checked as described by Marsh et al. (1982).

Media. The London Hospital (LH) medium of Hardie \& Bowden (1974), as modified by Keevil et al. (1984), was used for the studies in which the $\mathrm{K}^{+} / \mathrm{Na}^{+}$ratios of the medium were to be manipulated. LHS and LHP media contained $100 \mathrm{~mm}-\mathrm{Na}^{+}$and $100 \mathrm{~mm}-\mathrm{K}^{+}$, respectively.

Growth conditions. Batch cultures of $S$. sanguis were grown at $37^{\circ} \mathrm{C}$ in a magnetically stirred 1 litre pyrex vessel with two side arms (Bellco Biological Glassware \& Equipment). An autoclavable pH electrode (Russell pH Ltd) was incorporated through one of the side arms of the vessel and a pH of $7.00 \pm 0.05$ was maintained automatically with either $2 \mathrm{M}-\mathrm{KOH}$ or $2 \mathrm{M}-\mathrm{NaOH}$, depending on the $\mathrm{K}^{+} / \mathrm{Na}^{+}$ratio required in the culture. The ionophores valinomycin, gramicidin and nigericin were dissolved in dimethyl sulphoxide (DMSO), sterilized by filtration and added to LH medium containing the equivalent of $100 \mathrm{mM}-\mathrm{K}^{+}$, immediately before inoculation. The final concentration of ionophore was $2.6 \mu \mathrm{M}$ (West et al., 1984). Control experiments with equivalent volumes of DMSO had no effect on growth or enzyme production. Batch cultures with Tween 80 contained $0.05 \%(v / v)$ of the detergent (Wittenberger et al., 1978) which was autoclaved separately before addition to the bulk medium.

Harvesting of cells. Bacteria were harvested in late exponential phase by centrifugation at $8000 \mathrm{~g}$ for $15 \mathrm{~min}$. The clarified culture supernatants were assayed for glycosyltransferase activities and the pelleted cells were prepared for fatty acid analysis.

Glycosyltransferase assays. The supernatants obtained on harvesting the organisms were prepared for glycosyltransferase assays using the method of Keevil et al. (1984). In short, supernatants were incubated at $37^{\circ} \mathrm{C}$ for $2 \mathrm{~h}$ in a solution buffered at pH 6.0 containing $5 \%(\mathrm{w} / \mathrm{v})$ sucrose as substrate. The water-insoluble polysaccharides made by the glycosyltransferase enzymes were precipitated in the aqueous phase during incubation whereas the water-soluble polysaccharides were precipitated using $80 \%(\mathrm{v} / \mathrm{v})$ ethanol (final concentration). Glucans and fructans were assayed using the methods of Dubois et al. (1956) and Kulka (1956).

Fatty acid analysis. Harvested cells were washed three times in distilled water to remove residual supernatant, and freeze-dried. The lyophilized bacteria were methylated and prepared for TLC using the method of Minnikin $e t$ al. (1975). Briefly, $50 \mathrm{mg}$ lyophilized material was mixed with $10 \mathrm{ml}$ of methanol/toluene $(1: 1$, v/v) in PTFEcapped tubes. Concentrated sulphuric acid $(0.2 \mathrm{ml})$ was added to each tube and these were incubated at $50^{\circ} \mathrm{C}$ for 
$16 \mathrm{~h}$. In the initial procedure to extract the fatty acid methyl esters the mixture was allowed to cool to room temperature and $20 \mathrm{ml}$ hexane was added. The mixture was stirred using a vortex mixer and was centrifuged at $3000 \mathrm{~g}$ for $5 \mathrm{~min}$. The fatty acid methyl esters from the upper layer of the mixture were separated and purified initially on preparative thin-layer plates coated with Kieselgel 60 (Merck) and the chromatograms were developed in light petroleum (b.p. $\left.60-80^{\circ} \mathrm{C}\right) /$ diethyl ether $(85: 15, \mathrm{v} / \mathrm{v})$. The area across the plate corresponding to the fatty acid band was scraped off and eluted with chloroform. The extracted fatty acid esters were identified by capillary GLC using a Fractovap 2150 flame ionization gas chromatograph containing a $25 \mathrm{~m}$ fused silica SE54 column (Carlo Erba, Milan, Italy). This was operated isothermally at $180^{\circ} \mathrm{C}$ using helium as the carrier gas $\left(1.0 \mathrm{ml} \mathrm{min}^{-1}\right)$. The individual esters were identified and quantified by comparing their retention times with those of standard fatty acid esters.

Subsequently, an alternative procedure was used to extract fatty acid methyl esters from the methylation reaction mixture (see above). In this procedure $0.5 \mathrm{ml}$ of saturated aqueous $\mathrm{NaCl}$ solution was added to the mixture and the fatty acid methyl esters were extracted with $2 \mathrm{ml}$ hexane/chloroform $(4: 1, \mathrm{v} / \mathrm{v})$. The fatty acids were quantified by capillary GLC and GLC/MS (Wait \& Hudson, 1985), which gave essentially identical results to the original TLC procedure.

\section{RESULTS}

\section{Effects of cations, ionophores and Tween 80 on GTF and FTF production}

The GTF-S activities of $S$. sanguis NCTC 7865 were similar when the organisms were grown in a high concentration of $\mathrm{Na}^{+}$(LHS) or $\mathrm{K}^{+}$(LHP) (Fig. 1). Tween 80 increased GTF-S activity by at least $50 \%$ whereas the addition of valinomycin, nigericin or gramicidin to LHP reduced enzyme activity by $20 \%, 30 \%$ and $60 \%$, respectively (Fig. 1). In contrast, the cation composition of the growth medium markedly affected FTF-S activity. Growth in LHS reduced the FTF-S activity by at least $50 \%$ of that found when the organisms were grown in either LHP or LHP with Tween 80. During growth in the presence of the ionophores no FTF-S activity could be detected. FTF-I activity was low or negligible under all growth conditions.

\section{Effects of cations on membrane fatty acids}

The membrane fatty acid profiles of $S$. sanguis NCTC 7865 were not affected by the cation composition of the medium. Cells harvested from either LHS or LHP in the late exponential phase of growth were similar in fatty acid composition, and in their ratio of unsaturated : saturated fatty acids $(0.63$ and 0.64 , respectively) (Table 1$)$.

\section{Effects of ionophores on membrane fatty acids}

Bacteria grown in the presence of ionophores exhibited significant differences in their fatty acid profiles (Table 1) although the ionophores varied in their potency. Valinomycin had the least effect, whereas gramicidin has the greatest influence, although all the ionophores tested reduced the unsaturated : saturated ratio. Decreases in hexadecenoic acid $\left(C_{16: 1}\right)$ content were observed, particularly in the presence of gramicidin and nigericin, which dissipate $\Delta \mathrm{pH}$.

Significant decreases in octadecenoic acid $\left(C_{18: 1}\right)$ were also observed when $S$. sanguis was grown in the presence of the ionophores. This was complemented by an increase in octadecanoic acid $\left(\mathrm{C}_{18: 0}\right)$ (Table 1). Octadecanoic acid : octadecenoic acid ratios of about $1: 1$ were observed in $S$. sanguis grown in the presence of gramicidin. Growth in the presence of nigericin and valinomycin gave ratios of 0.67 and 0.59 , respectively, which again were significantly higher than those of control samples $(0 \cdot 36)$.

Interestingly, nigericin (which reduces $\Delta \mathrm{pH}$ ) had a more pronounced effect on the $\mathrm{C}_{18: 0}: \mathrm{C}_{18: 1}$ ratio than did valinomycin which lowers $\Delta \psi$. Reducing both $\Delta \mathrm{pH}$ and $\Delta \psi$ with gramicidin gave the greatest decrease in the $\mathrm{C}_{18: 0}: \mathrm{C}_{18: 1}$ ratio; this change was in addition to those observed when either $\Delta \mathrm{pH}$ or $\Delta \psi$ was lowered.

\section{Effect of Tween 80 on membrane fatty acids}

The above results suggest a correlation between the proportion of unsaturated fatty acids, specifically octadecenoic acid $\left(\mathrm{C}_{18: 1}\right)$, and the secretion of GTF-S. This was investigated further by growing $S$. sanguis in the presence of Tween 80 , in an attempt to increase the proportion of 


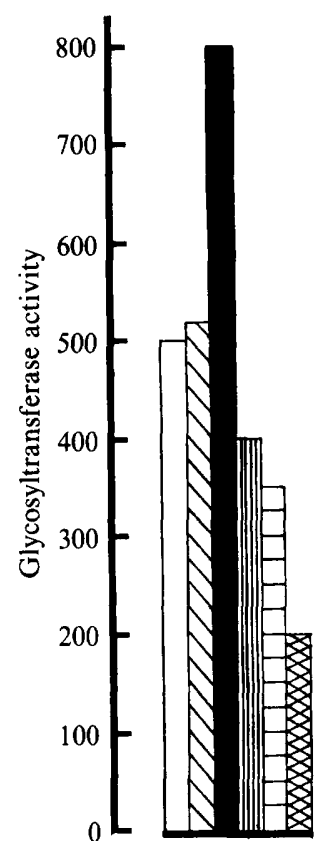

GTF-S

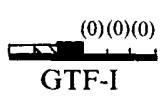

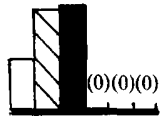

FTF-S

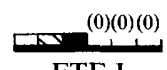

FTF-I

Fig. 1. Effect of cations, pmf inhibitors and Tween 80 on the glycosyltransferase activities of $S$. sanguis

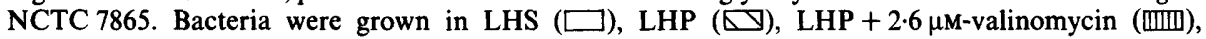
nigericin $(\Xi)$ or gramicidin $(\bigotimes)$, or LHP plus $0.05 \%(\mathrm{v} / \mathrm{v})$ Tween $80(\mathrm{U})$ at $\mathrm{pH} 7.0$ and harvested in the late exponential phase of growth. The clarified supernatants were then used for glycosyltransferase enzyme assays. Each experiment was repeated with at least three independent cultures which gave essentially identical results. Units of transferase activity are $\mu \mathrm{g}$ glucose or fructose polymerized from sucrose $\mathrm{h}^{-1}(\mathrm{ml} \text { culture supernatant })^{-1}$.

Table 1. Membrane fatty acid composition of $S$. sanguis

Lyophilized cells of $S$. sanguis NCTC 7865, grown in LHS or LHP, or in LHP containing $2.6 \mu \mathrm{M}$ valinomycin, nigericin or gramicidin, or $0.05 \%(\mathrm{v} / \mathrm{v})$ Tween 80 , were prepared and analysed for long chain fatty acid content. Analyses are the means of at least five determinations made on cell membranes prepared from independent cultures. Variations between preparations were less than $10 \%$.

Fatty acid content (percentage of total)

Growth environment

$\overbrace{\begin{array}{c}\text { Tetra- } \\ \text { decanoic } \\ \left(C_{14: 0}\right)\end{array}}$

Hexa-
decanoic $\begin{gathered}\text { Hexa- } \\ \text { decenoic }\end{gathered}$

$$
\text { (C 16:0) }
$$$$
\left(\mathrm{C}_{16: 1}\right)
$$

$40 \cdot 6$

$44 \cdot 0$

$43 \cdot 0$

$38 \cdot 4$

$17 \cdot 4$

\section{$6 \cdot 2$}

6.4

$5 \cdot 3$

$3 \cdot 0$

$2 \cdot 4$

$8 \cdot 4$

$\begin{array}{cc}\text { Octa- } & \begin{array}{c}\text { Octa- } \\ \text { decanoic }\end{array} \\ \left(\mathrm{C}_{18: 0}\right) & \left(\mathrm{C}_{18: 1}\right)\end{array}$

$11 \cdot 8$

$11 \cdot 0$

14.0

$18 \cdot 1$

$25 \cdot 3$

$2 \cdot 2$
Unsaturated : saturated

$\begin{array}{ll}\text { fatty } & C_{18: 0}: \\ \text { acid } & C_{18: 1} \\ \text { ratio } & \text { ratio } \\ & \\ 0.63 & 0.38 \\ 0.64 & 0.36 \\ 0.44 & 0.59 \\ 0.45 & 0.67 \\ 0.41 & 0.98 \\ 2.20 & 0.044\end{array}$

octadecenoic acid $\left(\mathrm{C}_{18: 1}\right)$ (Jacques et al., 1985) above that normally found during growth in LHP.

The membrane fatty acid composition was dramatically altered by Tween 80 , principally by increasing the degree of unsaturated fatty acids with a concomitant decrease in the saturated fatty acids. Octadecenoic acid $\left(\mathrm{C}_{18: 1}\right)$ exhibited the greatest increase with the result that the $\mathrm{C}_{18: 0}: \mathrm{C}_{18: 1}$ ratio was only $0 \cdot 04$. 


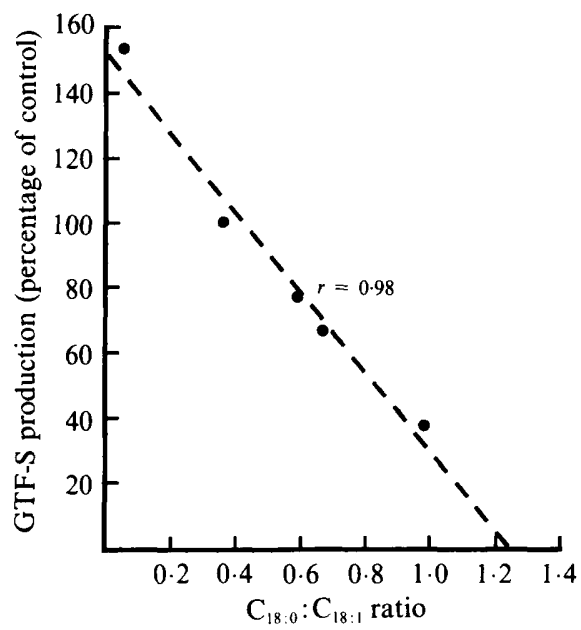

Fig. 2. Relationship between GTF-S production and the $\mathrm{C}_{18: 0}: \mathrm{C}_{18: 1}$ fatty acid ratio of $S$. sanguis grown with Tween 80 or in the presence or absence of the ionophores valinomycin, nigericin and gramicidin. Bacteria were grown and assayed for GTF-S as described in Fig. 1 and for fatty acids as described in Table 1. GTF-S production is expressed as a percentage of the untreated control value.

\section{DISCUSSION}

It has been suggested that the $\Delta \psi$ component of the pmf provides the primary energy requirement for extracellular enzyme secretion by Escherichia coli (Pagès \& Lazdunski, 1982). However, this notion has recently been disputed by Bakker \& Randall (1984) who concluded that the energy requirement is fulfilled by the total pmf. We too have suggested that both $\Delta \psi$ and $\Delta \mathrm{pH}$ are essential for FTF-S production in $S$. sanguis because high $\mathrm{Na}^{+}$concentrations and the presence of the ionophores valinomycin, nigericin or gramicidin greatly reduced or completely abolished pmf generation (Keevil \& Hamilton, 1984a,b) and the production of FTF-S (West $e t$ al., 1984). However, a different mechanism seemed to be operating in the production of GTF-S. This enzyme was not affected by high $\mathrm{Na}^{+}$concentrations and, unlike FTF-S, the ionophores were not totally inhibitory.

Markevics \& Jacques (1985) suggested that membrane fluidity rather than pmf per se is responsible for GTF production in $S$. salivarius. We therefore investigated this proposal by studying the membrane fatty acid profiles of $S$. sanguis and relating them to GTF-S production by this organism grown in high $\mathrm{K}^{+}$or $\mathrm{Na}^{+}$environments and in the presence of ionophores or Tween 80 .

Changes in the $\mathrm{Na}^{+}$and $\mathrm{K}^{+}$concentrations of the environment had no effect on the fatty acid profile of $S$. sanguis (Table 1). These results are contrary to the findings of Markevics \& Jacques (1985) using $S$. salivarius, who found that the unsaturated : saturated ratio increased when the $\mathrm{K}^{+}$ content of the medium was raised. This change was due mainly to an increase in the ratio of octadecenoic $\left(\mathrm{C}_{18: 1}\right)$ : octadecanoic $\left(\mathrm{C}_{18: 0}\right)$ acids. In $S$. sanguis, however, the ratio of these two fatty acids remained constant during growth in both high $\mathrm{Na}^{+}$and high $\mathrm{K}^{+}$concentrations. These results correlated with the observation that GTF-S but not FTF-S production was unaltered.

On summarizing the above findings it seemed that as the ratio of unsaturated to saturated fatty acids decreased, for example following the addition of valinomycin, nigericin or gramicidin, respectively, a reduction in GTF-S production occurred. Similarly, when the unsaturated to saturated fatty acid ratio was increased with Tween 80 , a pronounced increase in GTF-S was noted. No linear relationship was found between GTF-S production and this ratio. Nevertheless, a statistically significant association was found between the octadecanoic $\left(C_{18: 0}\right)$ :octadecenoic $\left(C_{18: 1}\right)$ acid ratio and the GTF-S activity (Fig. 2). This ratio increased from 0.044 , in the presence of Tween 80 , to 0.98 with gramicidin, and a corresponding decrease in GTF-S occurred. 
We propose, therefore, that GTF-S production in $S$. sanguis is influenced by the fatty acid composition of the membrane, particularly the octadecanoic $\left(C_{18: 0}\right)$ :octadecenoic $\left(C_{18: 1}\right)$ acid ratio. This might be due to an increase in the overall fluidity of the cytoplasmic membrane or to localized areas of fluidity, equivalent to a membrane 'pore', caused by the elevated proportions of unsaturated fatty acids (Gruner, 1985), facilitating enhanced GTF-S enzyme secretion.

The unaltered FTF-S activities observed in the presence of Tween 80 indicated that the production of this enzyme was not directly related to the fatty acid composition or the fluidity of the membrane. The ionophore experiments and growth in the presence of high $\mathrm{Na}^{+}$ concentrations confirm the importance of pmf in FTF-S production (West et al., 1984).

This work was supported in part by the Medical Research Council of Great Britain grant no. G8310210SB.

\section{REFERENCES}

Bakker, E. P. \& Randall, L. L. (1984). The requirement for energy during export of $\beta$-lactamase in Escherichia coli is fulfilled by the total protonmotive force. EMBO Journal 3, 895-900.

Carlsson, J., Grahnen, H., Jonsson, G. \& Wikner, S. (1970). Establishment of Streptococcus sanguis in the mouths of infants. Archives of Oral Biology 15, 1143-1148.

CoOney, C.L., Leung, J. \& Sinskey, A. J. (1976). Growth and physiology of Streptococcus mutans during transients in continuous culture. In Microbial Aspects of Dental Caries, pp. 799-808. Edited by $\mathrm{H}$. M. Stiles, W. J. Loesche \& T. C. O'Brien. Washington, DC: Information Retrieval Inc.

Dubois, M., Gillies, K. A., Hamilton, J. K., Rebers, P. A. \& SMith, F. (1956). Colorimetric method for determination of sugars and related substances. Analytical Chemistry 28, 350-356.

GibBons, R. J. \& van Houte, J. (1975). Bacterial adherence in oral microbial ecology. Annual Review of Microbiology 29, 19-44.

GruneR, S. M. (1985). Lipid polymorphism: the molecular basis of nonbilayer phases. Annual Review of Biophysiology and Biophysical Chemistry 14, 211238.

HARdie, J. M. \& Bowden, G. H. (1974). Cell wall and serological studies of Streptococcus mutans. Caries Research 8, 301-316.

Jacques, N. A., Jacques, V. L., Wolf, A. C. \& WITTENBERGER, C. L. (1985). Does an increase in membrane unsaturated fatty acids account for Tween 80 stimulation of glucosyltransferase secretion by Streptococcus salivarius? Journal of General Microbiology 131, 67-72.

Keevil, C. W. \& Hamilton, I. R. (1984a). Comparison of polyvinyl chloride membrane electrodes sensitive to alkylphosphonium ions for the determination of the electrical difference $(\Delta \psi)$ of Streptococcus mutans and Lactobacillus casei. Analytical Biochemistry 139, 228-236.

KeEVIL, C. W. \& Hamilton, I. R. (1984b). Influence of $\mathrm{Na}^{+}$and $\mathrm{K}^{+}$on generation of protonmotive force and glucose uptake and metabolism in oral bacteria. Journal of Dental Research 63, 495.

Keevil, C. W., West, A. A., Bourne, N. \& Marsh, P. D. (1983). Synthesis of a fructosyltransferase by Streptococcus sanguis. FEMS Microbiology Letters 20, 155-157.

Keevil, C. W., West, A. A., Bourne, N. \& Marsh, P. D. (1984). Inhibition of extracellular glucosyl- and fructosyltransferase synthesis and secretion in Streptococcus sanguis by sodium ions. Journal of General Microbiology 130, 77-82.

Keevil, C. W., MCDermid, A. S., Marsh, P. D. \& ElLwOOD, D. C. (1986). Protonmotive force driven 6-deoxyglucose uptake by the oral pathogen Streptococcus mutans Ingbritt. Archives of Microbiology 146, $118-124$.

KUlKA, R. G. (1956). Colorimetric estimation of ketopentoses and ketohexoses. Biochemical Journal 63, 542-549.

Markevics, L. J. \& JACQUes, N. A. (1985). Enhanced secretion of glucosyltransferase by changes in potassium ion concentration is accompanied by an altered pattern of membrane fatty acids in Streptococcus salivarius. Journal of Bacteriology 161, 989-994.

Marsh, P. D., Williamson, M. I., Keevil, C. W., McDermid, A. S. \& Ellwood, D. C. (1982). Influence of sodium and potassium ions on acid production by washed cells of Streptococcus mutans Ingbritt and Streptococcus sanguis NCTC 7865 grown in a chemostat. Infection and Immunity 36, 476-483.

Marsh, P. D., Keevil, C. W. \& Ellwood, D. C. (1984). Relationship of bioenergetic processes to the pathogenic properties of oral bacteria. Journal of Dental Research 63, 401-406.

Minnikin, D. E., Alshamaony, L. \& Goodfellow, M. (1975). Differentiation of Mycobacterium, Nocardia and related taxa by thin-layer chromatography analysis of whole organism methanolysates. Journal of General Microbiology 88, 200-204.

PAGÈs, J. M. \& LAzdunski, C. (1982). Membrane potential $(\Delta \psi)$ depolarising agents inhibit maturation of exported proteins in Eschericha coli. FEBS Letters 149, 51-54.

WAIT, R. \& HudSON, M. J. (1985). The use of picolinyl esters for the characterization of microbial lipids: application to the unsaturated and cyclopropane fatty acids of Campylobacter species. Letters in Applied Microbiology 1, 95-99.

West, A. A., KeEVIL, C. W., Marsh, P. D. \& ElLwOOD, D. C. (1984). The effect of ionophores on growth and glycosyltransferase production of Streptococcus sanguis. FEMS Microbiology Letters 25, 133-137.

Wittenberger, C. L., Beaman, A. J. \& Lee, L. N. (1978). Tween 80 effect on glucosyltransferase synthesis by Streptococcus salivarius. Journal of Bacteriology 133, 231-239. 